DOI: $10.17805 / z p u .2017 .4 .22$

\title{
Первое издание «Сонетов» Шекспира в академической серии «Литературные памятники»
}

\author{
B. C. МАKAPOB
}

ПРАВОСЛАВНЫЙ СВЯТО-ТИХОНОВСКИЙ ГУМАНИТАРНЫЙ УНИВЕРСИТЕТ, Г. МОСКВА,

E. A. ПЕРВУШИНА

ДАЛЬНЕВОСТОЧНЫЙ ФЕДЕРАЛЬНЫЙ УНИВЕРСИТЕТ, Г. ВЛАДИВОСТОК,

B. С. ФЛОРОВА

МОСКОВСКИЙ ПЕДАГОГИЧЕСКИЙ ГОСУДАРСТВЕННЫЙ УНИВЕРСИТЕТ,

Е. В. ХАЛТРИН-ХАЛТУРИНА

ИНСТИТУТ МИРОВОЙ ЛИТЕРАТУРЫ ИМ. А. М. ГОРЬКОГО РАН, Г. МОСКВА

Подготовители академического издания «Сонетов» Шекспира размышляют об общей концепции издания - двуязычного и включающего в себя несколько вариантов перевода шекспировского сонетного цикла. Издание учитывает последние достижения мирового шекспироведения и обобщает опыт многих изданий “Сонетов», вышедших в последние десятилетия.

Ключевые слова: У. Шекспир; сонеты; английская литература; русская литература; переводы

ля российского шекспироведения, так же как и для мирового, 2014-2016 гг. стали знаковыми датами: в 2014 г. широко отмечался 450-летний юбилей великого англииского поэта и драматурга, а в 2016 г. - 400-летие его памяти. Именно в это трехлетие русские шекспироведы провели большую работу по созданию и публикации первого в России издания «Сонетов» Шекспира в академической серии «Аитературные памятники».

Подготовка этой книги была заветной мечтой ученого секретаря Шекспировской комиссии РАН (впоследствии - заместитель председателя) И. С. Приходько. Именно Ирина Степановна собрала научный коллектив, состоявший из А. Н. Горбунова, Е. А. Первушиной и В. С. Флоровой, и подала заявку в одну из самых престижных отечественных филологических серий - «Иитературные памятники». Там инициатива И. С. Приходько была горячо поддержана, а Российский государственный научный фонд принял решение оказать проекту финансовую поддержку (проект РГНФ № 14-04-00531).

К сожалению, за большой радостью последовало огромное несчастье - полная сил и энергии И. С. Приходько неожиданно скончалась. Нереализованными остались ее планы по написанию научного комментария к каждому сонету и собственной статьи о шекспировской лирике.

Однако научный коллектив, собранный ею для подготовки издания, не опустил руки. Ощущая постоянную поддержку со стороны редколлегии серии «Аитературные памятники», руководства Института мировой литературы им. А. М. Горького (сотрудницей которого была И. С. Приходько) и Российского государственного научного фонда, подготовители привлекли к работе еще двух специалистов. В. С. Макаров написал комментарий к английскому тексту каждого стихотворения, а Е. В. ХалтринХалтурина - статью, аналога которой нет в научных собраниях шекспировской поэзии в Великобритании и США, - статью о роли сонетов в пьесах Шекспира, так называемых вставках, имеющих большое драматургическое значение. В свою очередь, 
Е. А. Первушина успешно закончила работу (которую начала еще при содействии И. С. Приходько) по отбору наиболее значимых русских переводов, не только достойно представляющих оригинал, но и являющихся важным свидетельством особенностей переводческой рецепции «Сонетов» в России. В. С. Флорова, наряду с написанием собственной статьи, взяла на себя общее руководство проектом, а А. Н. Горбунов выступил ответственным редактором всего издания.

Труд заново воссозданного авторского коллектива завершился в конце 2016 г. с выходом в свет книги «Уильям Шекспир. Сонеты» в серии «Аитературные памятники» в издательстве «Наука» (Шекспир, 2016). Как и любое издание этой широко известной филологической серии, книга состоит из трех частей. Первая - это собственно памятник, в данном случае напечатанный на языке оригинала. По решению авторского коллектива английский текст приводится по авторитетному Оксфордскому изданию 2002 г. (Shakespeare, 2002). Вторая, самая объемная часть - это переводы сонетов на русский язык. Открывают эту часть полные переводы всего цикла. Их отобрано пять: М. И. Чайковского (1914), С. Я. Маршака (1948), А. М. Финкеля (1976), Игн. М. Ивановского (2001) и В. Б. Микушевича (2004). Однако, разумеется, только ими русская шекспировская сонетиана отнюдь не исчерпывается. Поэтому завершается вторая часть книги настоящей поэтической антологией: здесь опубликованы наиболее удачные переводы почти пяти десятка авторов, начиная с XIX в. и заканчивая сегодняшним днем. Некоторые из этих работ печатаются впервые, и честь открытия новых переводчиков русскоязычному читателю принадлежит покойной И. С. Приходько и Е. А. Первушиной. В итоге читателям представлена небывало широкая картина русской переводческой сонетианы Шекспира.

Третья часть книги - наиболее важная в филологическом плане. Она содержит собственно научный аппарат: работы авторов-подготовителей, сопровождающие английский и русские тексты, и подстрочные примечания В. С. Макарова.

Открывает третью часть поистине энциклопедическая по содержательному охвату и аналитической глубине статья А. Н. Горбунова «Сонеты Шекспира: загадки и гипотезы» (Горбунов, 2016), которая вводит читателя в круг проблем - а он огромен, связанных с шекспировской лирикой. И каждая из них окружена множеством загадок, не дающих покоя исследователям как минимум уже три столетия. Говоря о первых изданиях сонетов Шекспира, А. Н. Горбунов знакомит читателей со спорами об истории их создания, о предполагаемом авторском участии в составлении цикла и его композиционных особенностях. При этом шекспировские стихи представлены в статье не изолированно, а в контексте богатейшей сонетной культуры XVI-XVII вв. ОАнако основное внимание исследователь, конечно, уделяет сонетам самого Шекспира, помогая читателям понять и оценить поэтическое великолепие его лиризма и неисчерпаемую глубину его художественной мысли. Анализируя особенности сонетного цикла Шекспира, А. Н. Горбунов не сводит его к ставшему банальным гипотетическому рассказу о любовных отношениях главных героев, хотя каждый из них получает в статье убедительно яркую характеристику. Автор прослеживает сложную диалектику и психологически насыщенный драматизм в развитии основных сонетных тем, показывает их внутреннюю взаимосвязь и богатство. Не случайно о лирической поэзии Шекспира не перестают думать и спорить. Особо А. Н. Горбунов останавливается на читательской и переводческой рецепции «Сонетов» в России. Он не только очерчивает проблемное поле, в котором существует поэзия Шекспира, но и рассказывает об основных путях решения многих спорных вопросов. По прочтении этой работы чита- 
тель оказывается подготовленным к восприятию тех уже более узкоспециальных статей, которые продолжают развивать темы, затронутые А. Н. Горбуновым.

Так, статья В. С. Флоровой «Основные тенденции и подходы к изучению шекспировских сонетов в английской критике XVII-XX веков» (Флорова, 2016) посвящена освещению текстологической проблемы изучения «Сонетов», а также истории их критического осмысления в Великобритании и других странах за три столетия. В отличие от шекспировских пьес «Сонеты» далеко не сразу стали широко известны и признаны. Первые отзывы о них чрезвычайно скудны - в сущности, отзыв всего один, если не считать предисловия Аж. Бенсона ко второму сфальсифицированному изданию. Это обстоятельство заставляет многих ученых думать, что большая часть тиража первого издания была изъята из продажи и уничтожена. В. С. Флорова последовательно описывает историю «открытия» шекспировских «Сонетов» издателями, критикой и широкой читательской аудиторией. Так, в конце XVIII в. восстановление первопечатного текста сопровождалось резким неприятием того факта, что основным адресатом шекспировского цикла выступает мужчина. В попытках объяснить эту «странность» критика следующего, XIX столетия предложила несколько гипотез. Прежде всего, это гипотеза о существенном автобиографизме сонетов, которые, таким образом, объявлялись свидетельством реальной жизни поэта, и, напротив, гипотеза об их чисто литературном характере, согласно которой сонеты являлись только своего рода «упражнениями на тему». Особенно В. С. Флорова останавливается на вопросе о влиянии на Шекспира платонических и неоплатонических теорий любви, распространенных в его время, а также на особенностях современного постмодернистского понимания шекспировского цикла - понимания, которое категорически отрицает существование цикла как поэтической целостности вообще.

В статье Е. А. Первушиной «"Но смерть поправ, до будущих времен дойдет мой стих...” (сонеты Шекспира в русских переводах)» (Первушина, 2016) представлен обстоятельный обзор переводческой рецепции шекспировских стихов в России. Она начала формироваться в XIX столетии, а в настоящее время стала одним из самых репрезентативных образцов переводной множественности в истории отечественной переводной литературы. Е. А. Первушина дает в своей работе не только богатую информацию об истории русских переводов сонетов Шекспира, но и убедительную концепцию этой истории. Отдавая должное С. Я. Маршаку, чьи переводы стали поистине звездным часом русской сонетианы Шекспира, Е. А. Первушина убеждает читателей в том, что для появления таких мастеров была необходима художественная почва, поэтически обработанная не только открытиями, но и неудачами предшественников. Авторы XIX и первой половины XX столетий возделали эту почву и, пробудив в России интерес к сонетам Шекспира, показали, что его стихи не могли переводиться только с языка на язык - они переводились с поэзии на поэзию, главным образом романтическую. А переводческий успех С. Я. Маршака, усиливший интерес к лирике Шекспира, стимулировал потребность в новых переводческих стратегиях и в значительной мере способствовал невероятному росту синхронической множественности параллельных переводов. Несмотря на многочисленность и разнообразие этих переводческих прочтений сонетов, делает вывод Е. А. Первушина, очевидно стремление современных авторов освободить шекспировские стихи от академизма пафосной романтизации.

В статье Е.В. Халтрин-Халтуриной «Сонетные вставки в пьесах Шекспира» (Халтрин-Халтурина, 2016) рассматриваются сонеты, являющиеся органической 
частью четырех шекспировских пьес. Это «Бесплодные усилия любви» (ок. 1594-1595: цикл из восьми сонетов, многие из которых «неправильные»), «Ромео и Ажульетта» (ок. 1595, три полных сонета и сонетные отрывки), «Много шума из ничего» (ок. 1598-1600; один неполный сонет) и «Все хорошо, что хорошо кончается» (ок. 1604; два сонета). Большее внимание уделено первым двум пьесам, так как сонеты играют в них определяющую роль. Упоминаются сонеты и из других пьес (например, из «Генриха V »). Названные пьесы могут пролить дополнительный свет на искусство Шекспира-сонетиста, так как в них для толкования вставных стихов имеются идеальные условия: дано описание ситуации, в которой создан и произнесен сонет, предоставлена внятная характеристика авторов и адресатов сонетов. Не вызывает дополнительных вопросов и порядок расположения 14-стиший, если таковых в пьесе несколько.

На сцене персонажи Шекспира произносят не только образцовые, но и ученические сонеты. Иногда шекспировские герои комментируют и вышучивают поэтические неудачи. Эксперименты Шекспира с сонетом очень разнообразны. В его пьесах сонетные вставки принимают форму писем, важных документов, живых диалогов. Адресовать сонет может не только любящий к любимой или любящая к любимому, но и мать - дочери, невестка - свекрови. А объектом воспеваний в сонете может быть будущий зять или сбежавший муж. Привычка ассоциировать сонеты Шекспира с тремя лицами - «Прекрасный юноша», «Поэт-соперник» и «Смуглая дама» - выработалась у широкой читательской аудитории потому, что сонеты, включенные Шекспиром в пьесы, исследователи обычно рассматривают исключительно в контексте той или иной драматической канвы. Между тем галерея персонажей, от лица которых и в адрес которых - Шекспир писал сонеты, гораздо шире. Именно о них и повествуется в названной статье.

В примечаниях В. С. Макарова (Примечания, 2016) для российского читателя обобщены достижения мирового шекспироведения за последние полвека. Наиболее заметная тенденция за этот период выразилась в повороте от биографического прочтения сонетов к жанровому. Если в XIX и начале XX в. шекспироведы в целом соглашались со знаменитой строкой Вордсворта о сонетах как «ключе, которым Шекспир отпер свое сердце», то начиная с 1920-х годов они все чаще рассматривают сонеты в контексте аналогичных циклов, созданных современниками Шекспира - Ф. Сидни, С. Аэниэлом, Г. Констеблом и др. Это необходимо было учесть при составлении примечаний - как и параллели между сонетами и шекспировскими пьесами. В отличие от других сонетистов, Шекспир был гениальным драматургом, что не могло не отразиться в особенном, драматическом языке его сонетов.

Отход от биографического прочтения сонетов проявился еще и в том, что более не ставится задача определить, кто был прототипом «Прекрасного юноши», «Смуглой дамы» и «Поэта-соперника». Эти образы многим обязаны предыдущей сонетной традиции, как английской, так и континентальной, и вместо бесконечного перебора кандидатов гораздо продуктивнее сосредоточиться на том, как построены эти персонажи и какова динамика их отношений с Поэтом как героем сонетного цикла.

Традиционно для серии «Иитературные памятники» книга шекспировских «Сонетов» сопровождается богатым иллюстративным материалом: факсимиле титульных страниц их первого издания (Кварто 1609 г.) и факсимиле книг с отзывами современников о шекспировской лирике. Приведено также факсимиле любопытного письма, в котором упоминается о покупке Кварто летом 1609 г. В альбоме-вклейке также можно увидеть портреты гипотетических адресатов шекспировской поэзии и поэтов- 
соперников, виды ра, который считается единственным прижизненным изображением драматурга. Этот же портрет, но уже в цвете, воспроизведен и на суперобложке издания. Таким образом, новое издание сонетов Шекспира в академической серии «Иитературные памятники» отражает наиболее значительные переводческие прочтения и современные научные подходы к проблемам, связанным с шекспировской поэзией.

\section{СПИСОК АИТЕРАТУРЫ}

Горбунов, А. Н. (2016) Сонеты Шекспира: загадки и гипотезы // Шекспир, У. Сонеты / изд. подгот. А. Н. Горбунов, В. С. Макаров, Е. А. Первушина, В. С. Флорова, Е. В. Халтрин-Халтурина ; отв. ред. А. Н. Горбунов. М. : Наука. 884 с. С. 607-649.

Первушина, Е. А. (2016) «Но смерть поправ, до будущих времен дойдет мой стих...» (сонеты Шекспира в русских переводах) // Шекспир, У. Сонеты / изд. подгот. А. Н. Горбунов, В. С. Макаров, Е. А. Первушина, В. С. Флорова, Е. В. Халтрин-Халтурина ; отв. реА. А. Н. Горбунов. М. : Наука. 884 с. С. $686-724$.

Примечания (2016) / сост. В. С. Макаров // Шекспир, У. Сонеты / изд. подгот. А. Н. Горбунов, В. С. Макаров, Е.А. Первушина,В.С.Флорова, Е. В. Халтрин-Халтурина ; отв. ред. А. Н. Горбунов. М. : Наука. 884 с. С. $770-868$.

Флорова, В. С. (2016) Основные тенденции и подходы к изучению шекспировских сонетов в английской критике XVII-XX веков // Шекспир, У. Сонеты / изд. подгот. А. Н. Горбунов, В. С. Макаров, Е. А. Первушина, В. С. Флорова, Е. В. Халтрин-Халтурина ; отв. ред. А. Н. Горбунов. М. : Наука. 884 с. С. 650-685.

Халтрин-Халтурина, Е. В. (2016) Сонетные вставки в пьесах Шекспира // Шекспир, У. Сонеты / изд. подгот. А. Н. Горбунов, В. С. Макаров, Е. А. Первушина, В. С. Флорова, Е. В. ХалтринХалтурина ; отв. ред. А. Н. Горбунов. М. : Наука. 884 с. С. 725-769.

Шекспир, У. (2016) Сонеты / изд. подгот. А. Н. Горбунов, В. С. Макаров, Е. А. Первушина, В. С. Флорова, Е. В. Халтрин-Халтурина ; отв. ред. А. Н. Горбунов. М. : Наука. 884 с.

Shakespeare, W. (2002) The complete sonnets and poems / ed. by C. Burrow. Oxford: Oxford University Press. ix, 750 p. (Oxford World's Classics).

Аата поступления: 11.12.2016 2.

THE FIRST EDITION OF W. SHAKESPEARE'S SONNETS

IN THE ACADEMIC SERIES "LITERARY MONUMENTS"

V. S. MAKAROV

ST. TIKHON'S ORTHODOX UNIVERSITY, MOSCOW,

E. A. PERVUSHINA

FAR EASTERN FEDERAL UNIVERSITY, VLADIVOSTOK,

V. S. FLOROVA

MOSCOW STATE UNIVERSITY OF EDUCATION (MSPU),

E. V. HALTRIN-KHALTURINA

GORKY INSTITUTE OF WORLD LITERATURE, MOSCOW

Shakespeare W. Sonety [Sonnets] / ed. by A. N. Gorbunov, V. S. Makarov, E. A. Pervushina, V. S. Florova and E. V. Haltrin-Khalturina; editor-in-chief A. N. Gorbunov. Moscow, Nauka Publ., 2016. 884 p. (Series: Literaturnye pamiatniki). ISBN 978-5-02-039223-6 (In Russ.).

In this article, the editorial team of the Russian academic edition of William Shakespeare's "Sonnets" discuss the general concept of the bilingual edition, which comprises several full translations of the sonnet cycle, as well as additional versions by a number of both famous and little-known translators. The book builds on the latest developments in global Shakespeare studies and summarizes the experience of numerous editions of Shakespeare's "Sonnets" published in the recent decades. 
Keywords: W. Shakespeare; sonnets; English literature; Russian literature; translations

\section{REFERENCES}

Gorbunov, A. N. (2016) Sonety Shekspira: zagadki i gipotezy. In: Shakespeare, W. Sonety / prepared by A. N. Gorbunov, V. S. Makarov, E. A. Pervushina, V. S. Florova and E. V. KhaltrinKhalturina ; ed. by A. N. Gorbunov. Moscow, Nauka Publ. 884 p. Pp. 607-649. (In Russ.).

Pervushina, E. A. (2016) «No smert' poprav, do budushchikh vremen doidet moi stikh...» (sonety Shekspira v russkikh perevodakh). In: Shakespeare, W. Sonety / prepared by A. N. Gorbunov, V. S. Makarov, E. A. Pervushina, V. S. Florova and E. V. Khaltrin-Khalturina ; ed. by A. N. Gorbunov. Moscow, Nauka Publ. 884 p. Pp. 686-724. (In Russ.).

Primechaniia (2016) / comp. by V. S. Makarov. In: Shakespeare, W. Sonety / prepared by A. N. Gorbunov, V. S. Makarov, E. A. Pervushina, V. S. Florova and E. V. Khaltrin-Khalturina ; ed. by A. N. Gorbunov. Moscow, Nauka Publ. 884 p. Pp. 770-868. (In Russ.).

Florova, V.S. (2016) Osnovnye tendentsii i podkhody k izucheniiu shekspirovskikh sonetov v angliiskoi kritike XVII-XX vekov. In: Shakespeare, W. Sonety / prepared by A. N. Gorbunov, V. S. Makarov, E. A. Pervushina, V. S. Florova and E. V. Khaltrin-Khalturina ; ed. by A. N. Gorbunov. Moscow, Nauka Publ. 884 p. Pp. 650-685. (In Russ.).

Khaltrin-Khalturina, E. V. (2016) Sonetnye vstavki v p'esakh Shekspira. In: Shakespeare, W. Sonety/prepared by A. N. Gorbunov, V. S. Makarov, E. A. Pervushina, V. S. Florova and E. V. Khaltrin-Khalturina ; ed. by A. N. Gorbunov. Moscow, Nauka Publ. 884 p. Pp. 725-769. (In Russ.).

Shakespeare, W. (2016) Sonety / prepared by A. N. Gorbunov, V. S. Makarov, E. A. Pervushina, V. S. Florova and E. V. Khaltrin-Khalturina ; ed. by A. N. Gorbunov. Moscow, Nauka Publ. 884 p. (Series: Literaturnye pamiatniki). (In Russ.).

Shakespeare, W. (2002) The complete sonnets and poems / ed. by C. Burrow. Oxford, Oxford University Press. ix, 750 p. (Oxford World's Classics).

Submission date: 11.12 .2016$.

Макаров Владимир Сергеевич - кандидат филологических наук, доцент кафедры германской филологии Православного Свято-Тихоновского гуманитарного университета. Адрес: 109651, Россия, г. Москва, ул. Иловайская, д. 9, корп. 2. Тел.: +7 (495) 646-71-38. E-mail: mail@ vmakarov.name

Первушина Елена Александровна - доктор филологических наук, доцент, профессор Восточного института - Школы региональных и международных исследований Аальневосточного федерального университета, почетный работник высшего профессионального образования РФ. Адрес: 690950, Россия, г. Владивосток, ул. Суханова, А. 8. Тел.: +7 (423) 265-24-29; +7 (423) 243-34-72. Эл. адрес: pervushelena@yandex.ru

Флорова Валерия Сергеевна - кандидат философских наук, доцент кафедры философии Московского педагогического государственного университета, член Шекспировской комиссии при Научном совете «История мировой культуры» РАН. Адрес: 119571, Россия, Москва, проспект Вернадского, д. 88. Тел.: +7 (495) 438-17-26. Эл. адрес: vsflorova@rambler.ru

Халтрин-Халтурина Елена Владимировна - доктор филологических наук, доктор философии $(\mathrm{PhD})$, старший научный сотрудник Отдела классических литератур Запада и сравнительного литературоведения Института мировой литературы им. А. М. Горького РАН (Москва). Тел.: +7 (495)690-50-30,+7 (495) 690-56-36. Эл. aдpec: elenahaltrin@yandex.ru

Makarov Vladimir Sergeevich, Candidate of Philology, Associate Professor, Department of Germanic Philology, St. Tikhon's Orthodox University. Postal address: Bldg. 2, 9 Ilovaiskaya St., 109651 Moscow, Russian Federation. Tel.: +7 (495) 646-71-38. E-mail: mail@vmakarov.name

Pervushina Elena Aleksandrovna, Doctor of Philology, Professor, Institute of Oriental Studies School of Regional and International Studies, Far Eastern Federal University, Honoured worker of 
higher vocational education. Postal address: 8 Sukhanova St., 690950 Vladivostok, Russian Federation. Tel.: +7 (423) 265-24-29; +7 (423) 243-34-72. E-mail: pervushelena@yandex.ru

Florova Valeria Sergeyevna, Candidate of Philosophy, Associate Professor, Department of Philosophy, Moscow State University of Education (MSPU); Member, Shakespeare Committee, Russian Academy of Sciences. Postal address: 88 Vernadsky Prospekt, 119571 Moscow, Russian Federation. Tel.:+7 (495) 438-17-26. E-mail: vsflorova@rambler.ru

Haltrin-Khalturina Elena Vladimirovna, Doctor of Philology, PhD, Senior Researcher, Department of Classical Western Literatures and Comparative Literary Studies, Gorky Institute of World Literature (IMLI), Russian Academy of Sciences (Moscow). Tel.: +7 (495) 690-50-30, +7 (495) 690-56-36. E-mail: elenahaltrin@yandex.ru 